\title{
9
}

\section{TEACHnology: Linking Teaching and Technology in Faculty Development}

\author{
Mei-Yau Shih
}

Mary Deane Sorcinelli

University of Massachusetts, Amherst

As a coordinator of teaching technologies and director of a center for teaching in a large research university, we have worked collaboratively over the last year to achieve a common goal: to implement and refine several faculty development initiatives that create linkages among the domains of teaching, learning, and technology. In this case study, we will describe the kinds of programs we've developed and summarize lessons we've learned. We hope that faculty developers on other campuses who are grappling with bow to define their mission related to technology and bow 10 work with faculty to integrate teaching and teclmology can adapt some of what has worked well for us.

The use of instructional media in the classroom has long been identiIfied as a "fourth revolution" in education (Ashby, 1967). It has the potential to reshape the role of the instructor from a knowledge conveyer to a guide and coach, while students take a more active role in the learning process. No longer are the textbook and instructor the sources of all knowledge; instead, the faculty member becomes the director of the knowledge-access process (Heinich, Molenda, Russell, \& Smaldino, 1996). In this way, instructional technology refers not so much to the actual use of technological tools as much as it does to the process of developing overall goals and strategies for enhancing teaching and learning that incorporate these tools. At its best, technology-based learning can help teachers support a wider range of learning styles, facilitate active 
learning in the classroom, use faculty time and expertise more effectively, and familiarize students with technology that will be vital for their futures in the world of work.

In our experience, faculty are both greatly excited and daunted by the promise and power of teaching technologies. Our students have grown up in a "high technology" environment and are well adept at the use of TV, videotape, computers, and the Internet as information exchange tools. Many faculty, on the other hand, struggle to learn new technologies and to see how they might be useful to them as teachers. At the same time, administrators, eager to better use limited resources, are ramping up resources for technology and urging that faculty get on board. This combination of faculty members' intrinsic interest in learning something new, fear of falling behind in understanding of instructional technology, and awareness of institutional pressures to use technological innovations has presented faculty developers with a variety of instructional challenges. How can we best work together with faculty to explore methods for integrating teaching and technology in ways that create a better learning environment for students?

As a coordinator of teaching technologies and director of a center for teaching in a large research university, we have worked collaboratively over the last year to achieve a common goal: to implement and refine several faculty development initiatives that create linkages among the domains of teaching, learning, and technology. In this case study, we will describe the kinds of programs we've developed and summarize lessons we've learned.

\section{Needs Assessment}

The Center for Teaching's (CFT) efforts began in 1995-96 with a needs assessment of faculty chosen because of their visibility as "early innovators" who had already attempted to use technology in their teaching. A total of 20 interviews were conducted with faculty representing nearly all of our nine schools and colleges. Our discussions focused on how faculty were using teaching technologies, what was going well, and what wasn't working so well (see Appendix 1).

In summary, the needs assessment suggested the following. In order to implement teaching technologies, individual faculty need time, resources (equipment, support services, appropriate classroom space), and a higher degree of communication and coordination with other users. On an institutional level, the university needs to work toward 
reframing its reward structure to recognize efforts to use technology. There also should be a broad discussion of the value and implications of technology for our mission of teaching and learning.

\section{Setting out a Mission}

In response to the assessment, the CFT expanded its mission to address issues of instructional technology and its implications for teaching and learning. Clearly, the Center had neither the resources nor desire to become technology providers on campus. Instead, we defined our mission as follows:

- To support individual faculty efforts in their use of instructional technology by consulting on issues of good practice and clarity of teaching and learning goals, and to direct faculty to other relevant campus resources.

- To increase communication among users of technology in hopes of improving the human infrastructure related to this rapidly changing field.

- To coordinate efforts with other units on campus that provide technical expertise and support for instructional technology.

- To advocate for institutional support of individual efforts to create and implement instructional technology.

- To recognize and reward excellence in the use of instructional technology (Butcher, 1997).

\section{EARLY TEACHNology InITIATIVES}

We decided that our long-range plans should include several tiers of activities that would provide multiple points of entry into the use of teaching technologies. We sketched out ideas on a continuum-from "lower risk" activities (e.g., a written and web-based guide to resources, teaching and learning roundtables) to a program that asked faculty to engage in more intensive training (e.g., a year-long faculty fellowship).

During the $1995-96$ academic year we began by offering a Teaching Well with Technology campus-wide workshop series that included topics such as The Active Voice: Classroom Learning and Student Involvement, The Paperless Class: Teaching and Research Via the World Wide Web, 
and Engaging Students as Active Learners: Using Technology to Promote Learning in the Classroom. During the 1996-97 academic year we published and distributed a print and web-based resource, TEACHnology: A Guide to Teaching Technology Resources, and followed up with a series of Teaching-and-Learning-with-Technology roundtables. Each roundtable explored one of the key teaching technologies featured in the guide-presentation tools, computer-based instruction, classroom communication systems, and distance teaching and learning tools. We used faculty, listed as "peer innovators" in the guide, to facilitate the discussions. These three initiatives all offered accessible, low-risk ways for faculty to gain awareness of the wide variety of teaching technology resources available to them as teachers. We were now ready to launch the cornerstone of our teaching technologies initiative, an intensive, yearlong TEACHnology Senior Faculty Fellowship. The following section describes the development of this key program. We believe it is unique in the field in terms of goals, design, format, and outcomes.

\section{TeaCHnology: A Senior faculty Fellowship Program}

For over a decade, the Center for Teaching and the Provost's Office at the University of Massachusetts, Amherst have sponsored a Lilly Teaching Fellows Program, a highly successful faculty development program for promising junior faculty members. After initial funding of a three-year grant from the Lilly Endowment, the university committed the necessary resources to continue the program over the past decade. Former teaching fellows report a number of benefits derived from a year in the program and in their ensuing academic careers-new teaching skills and attitudes, collegial contacts, greater understanding of institutional expectations, and professional confidence (List, 1997).

From its inception, the Teaching Fellows Program was limited to pretenure faculty. Over the years, however, there have been many tenured faculty who felt that they, too, could gain from a similar experience. As noted earlier, teaching in the 1990 s has presented unique challenges that were not present in the past. We felt that senior faculty would benefit from a forum in which they could share information, discuss classroom experiences, and learn from each other.

Beyond the teaching technology activities occurring in our Center, several campus initiatives allowed us to move our vision of a senior faculty fellowship closer to reality. Our chancellor's multi-year strategic planning process included, from the start, a significant information tech- 
nology initiative. This initiative spearheaded the development and renovation of facilities; the installation of state-of-the-art equipment in lecture halls, classrooms, and computer labs; and a modest laptop computer loan program. The next step seemed to be to increase the human infrastructure of resources on campus. The university had focused on hardware and software; it was time to focus on "peopleware."

In 1997-98, we proposed and started our TEACHnology Senior Fellowship Program, building upon the goals and framework of the Lilly Teaching Fellows Program. Why focus on providing senior faculty with increased opportunities and support for integrating teaching technologies? Based on our earlier needs assessment, we found lots of evidence that it was our tenured faculty who were particularly interested in developing new computer-based paradigms for teaching and learning. In fact, nearly all of our faculty who were identified as "early adapters" were tenured. Rogers (1995) offers an explanation of faculty adoption of new technologies. He proposes that "innovators" and "early adapters" constitute 15 percent; traditional faculty-"the majority or mainstream"-constitute 70 percent; and "nonadopters" form the last 15 percent of the total faculty. Rogers emphasizes that the majority of faculty need assistance in "crossing the chasm" from the mainstream to the adapters. We found that tenured faculty at UMass included both a small group of "early adapters" and an enormous group of "mainstream" faculty seeking assistance in "crossing the chasm" (Sorcinelli, in press).

\section{Goals of the Program}

The major goals of the TEACHnology fellowship are to help senior faculty apply the capacities of technology to teaching and learning, particularly at the undergraduate level; to foster teaching innovations through technology; to increase communication and collaboration among users of technology; and to provide a special opportunity for renewal to senior faculty.

\section{Selection of Fellows}

The TEACHnology fellowship includes ten tenured fellows who are selected from across the nine schools and colleges on campus. The award is competitive; nominations are made by department chairs and reviewed by a selection committee. The program seeks tenured faculty who are teaching undergraduates, have a plan for integrating teaching technologies into a course, and are interested in disseminating what they 
have learned throughout their home departments and colleges. During the first two years, the program has attracted senior faculty who are both outstanding teachers and scholars. Fellows are awarded a state-of-the-art laptop computer with instructional software, funded by the deans of their schools and colleges.

\section{Program Elements}

The structure of the TEACHnology fellowship is a simple one. Each fellow chooses one course to work on and the goal is to integrate relevant teaching technologies and other teaching innovations into the course. Regular interaction among the fellows is a key ingredient. We open the fellowship year at a one-day retreat in the fall where fellows meet each other, learn about the project's goals and activities, and identify personal plans. Throughout the year, they participate in a seminar that meets every other week. Here fellows are introduced to instructional concepts that broaden their perspectives both as teachers and users of technology. They also share experiences, work on projects and examples, and practice implementation of course materials. Topics for such sessions include enhancing traditional teaching through technology (e.g., presentation tools such as PowerPoint); changing pedagogy with technology (e.g., collaborative learning, computer-assisted instruction); accommodating individual differences with technology; and connecting in- and out-ofclass learning with technology (e.g., email, World Wide Web). Outside of sessions, fellows consult individually or in small groups with our Center's coordinator of teaching technologies and other campus service providers. At the end of the academic year, the fellows have an integrated course designed, developed, tested, and evaluated. They also offer demonstrations of instructional materials to other colleagues through a department, college, or campus-wide forum.

\section{Program Outcomes}

Over the past two years, 20 faculty members have participated in the TEACHnology program. They report a number of benefits in terms of professional development. First, they indicate that they are much more informed as to what technologies are available to them and which service providers can best help them when they require assistance. The TEACHnology program also provides a supportive community in which the fellows interact with other fellows both during and beyond their year in the program. In addition, the program encourages senior faculty to form a cadre or network of "peer innovators" who can share expertise with col- 
leagues. Most importantly, the program promotes renewal and vitality in teaching by offering an opportunity for senior faculty to become learners again, rethinking their instructional objectives and their approaches to teaching, trying out new technologies, and integrating these ideas into their classes.

\section{Eight Lessons Learned}

We continue to work at figuring out the best options for promoting teaching development through teaching technologies. We have gleaned a few ideas about what it takes to make a program like this really work in terms of supporting faculty, especially in their role as teachers in the information age.

\section{1) Provide Incentives for Development}

Our senior fellows reported that one key attraction to the TEACHnology fellowship was that the grant required a simple application and provided a concrete award: a high-performance laptop computer, either a Power Mac or Pentium PC. Each laptop was loaded with software such as Claris Home Page, Publisher, and MS Office for their project development. We also built training in the use of each application into the program.

\section{2) Keep the Emphasis on Pedagogy vs. Hardware and Software} Although our Center provides various mini, hands-on training sessions to faculty as they develop their projects, the program continually focuses faculty attention on the pedagogical implications of using technology. At the bi-weekly seminar, concrete examples about ways in which technologies can benefit, or detract from, teaching and student learning are freely shared among the fellows.

\section{3) Offer a Range of Individual Support Services}

We soon recognized that the all-group seminars needed to be supplemented with individual support services. These support services included ongoing, one-on-one consultation with a trained teaching technology consultant in the Center, special access to other services providers on campus who could offer specific training (e.g., web design and multimedia projects), and access to a network of peers from the previous year's program. This structured yet flexible design was successful because faculty wanted to share ideas and also wanted training targeted directly to their individual needs. (They clearly indicated that they would not 
engage in activities that wasted time or were unrelated to their instructional situation.)

\section{4) Create Collegial Structure That Facilitates Dialogue}

Many faculty members experience a sense of isolation and express a desire for more collegiality, particularly in their roles as teachers. Our fellows also noted that they typically have few opportunities to interact with faculty members outside of their department or school/college. Fellows reported that the TEACHnology fellowship encouraged them to connect with, and help, each other by providing opportunities for peer learning during the bi-weekly seminars and by creating "networks" across the disciplines for research and teaching.

\section{5) Focus on Acquiring New Skills}

The TEACHnology fellowship is an ideal avenue for faculty development because it focuses on an area in which many faculty are novices (sometimes knowing less than their students) and are challenged as learners. At the same time, many faculty are eager and intrinsically motivated to learn technology applications necessary for their teaching and scholarship. They especially appreciate learning skills that take them to a new level (e.g., creating an instructional web site to support a large class, using presentation technology to engage students in the classroom, or forming email discussion groups for their classes). Like most adult learners, our senior fellows also responded best to learning through lots of "hands-on" practice rather than listening to presentations.

\section{6) Pay Attention to Non-Technological Teaching and Learning}

Technology is merely a tool to enhance learning; technology alone will not solve instructional problems. Instructional issues such as learner characteristics, learning outcomes, physical setting, and teaching style are at least as important as knowledge and skills in using technology. Dialogues among participating faculty across disciplines facilitated a better understanding of these non-technological issues; at the same time, our Center offered individual consultation to faculty to respond to specific instructional needs that extended beyond the use of technology.

\section{7) Seek Ways to Assess Teaching Technologies}

Our Center provides each fellow with opportunities for mid-term classroom assessment during the fellowship year. TEACHnology fellows each choose one course in which to get student and/or consultant feedback on their incorporation of teaching technologies. These sources of feedback 
(e.g., student focus groups or surveys, classroom observations) allow them to identify what is going well and what might merit attention. For example, when one fellow asked students what would make a PowerPoint presentation a better learning experience, some students suggested that the faculty member needed to slow down the pace while presenting the slides, and others suggested that the instructor engage in more interactive discussions associated with the presented information. When another faculty member used the PRS (an interactive Personal Response System) to promote active learning in class, most students responded positively in terms of the collaborative practices facilitated by the PRS. At the same time, some students perceived such interactive exercises as distracting. Such feedback opens up useful dialogues that go beyond the technology to instructional issues such as teaching goals, pacing, student learning differences, and peer and collaborative learning strategies.

\section{8) Create Ample Measures of Recognition and Reward}

Beyond modest financial support, our faculty expressed a need for something often vaguely described as respect or recognition. Senior faculty who have been "good citizens" and have put considerable time into developing as teachers and researchers, often remark that they receive little acknowledgment for such efforts. Beyond resources provided through the program, fellows are recognized in campus publications, awarded plaques, and acknowledged at our annual Celebration of Teaching Dinner, which draws several hundred students, staff, faculty, and administrators. This spring semester, a campus-wide teaching technology roundtable was hosted by the fellows from the first two years. They presented the range of teaching ideas and strategies that they have gathered from integrating technologies in their classrooms.

\section{Final Thoughts}

We learned a lot during the first two years of the TEACHnology Fellows Program, from development to implementation, from teaching to learning. At an individual level, participating faculty have learned to use computers and other instructional media to make their teaching more effective. They have become aware that the integration of technology involves more than physical setup and technical support; it requires some curricular modifications and instructional strategy shifts. Also, our tenured faculty fellows report positive effect in terms of an improved sense of collegiality, community, and morale. At the departmental level, the TEACHnology fellows have begun to emerge as exemplars who are 
eager to take risks and become mentors to colleagues who express interest in instructional technologies. Finally, the program has gained administrative support, particularly at the department, college, and provost levels and has raised awareness of the need for more faculty development opportunities that create linkages among teaching, learning, and technology.

\section{ACKNOWLEDGMENTS}

The authors would like to acknowledge former CFT Coordinators for Teaching Technologies, Amy Butcher and Lisa Isleb, who provided early leadership for this program.

\section{REFERENCES}

Ashby, E. (1967). Machines, understanding, and learning: Reflections on technology in education. The Graduate Journal, 7, 359-373.

Heinich, R., Molenda, M., Russell, J., \& Smaldino, S. (1996). Instructional media and technologies for learning (5th ed.). Englewood Cliffs, NJ: Prentice-Hall.

Butcher, A. (1997). TEACHnology: A guide to teaching technology resources at the University of Massachusetts, Amberst. Center for Teaching: University of Massachusetts, Amherst.

List, K. (1997). A continuing conversation on teaching: An evaluation of a decade-long Lilly Teaching Fellows Program 1986-1996. To Improve the Academy, 16, 201-224.

Rogers, E. M. (1995). Diffusion of innovation. (4th ed.). New York: NY Free Press.

Sorcinelli, M. D. (Fall, 1999). Post-tenure review through post-tenure development: What linking senior faculty and technology taught us. Innovative bigher education.

Conlacts:

Mei-Yau Shih

Center for Teaching

301 Goodell Building

University of Massachusetts Amherst

Amherst, MA 01003

(413) 545-1225

(413) 545-3829 (FAX)

mshih@acad.umass.edu 
Mary Deane Sorcinelli

Center For Teaching

301 Goodell Building

University of Massachusetts Amherst

Amherst, MA 01003

(413) 545-1225

(413) 545-3829 (FAX)

msorcinelli@acad.umass.edu

Mei-Yau Shih is Coordinator of Teaching Technologies at the Center for Teaching, University of Massachusetts, Amherst. She works with faculty on integrating technologies for teaching and learning in the classroom. She is currently coordinating the TEACHnology Fellows Program at the UMass Amherst campus. She joined the CFT in August 1998; before that, she was employed at Westmar University in LeMars, lowa, as Associate Academic Dean, Associate Professor, and Director of the Telecommunications Programs. She has developed and taught various instructional technology and telecommunications courses in the past seven years; some of her classes were offered over the interactive (fiber optics) network and the Internet.

Mary Deane Sorcinelli is Associate Provost, Director of the Center for Teaching, and Associate Professor, adjunct in the Department of Educational Policy and Research Administration, University of Massachusetts, Amherst. She also serves as visiting scholar to the American Association of Higher Education (AAHE) in Washington. She has consulted with hundreds of individual faculty members on teaching and has worked at departmental, school, campus-wide, and national levels to encourage support and recognition for good teaching. She publishes widely in the areas of academic career development and teaching improvement and evaluation. She also directs a number of external teaching development grants and teaches at the graduate level. 


\section{APPENDIX 9.1}

A total of 20 half-hour interviews were conducted with faculty from nine different colleges and schools of Natural Sciences and Mathematics, Humanities and Fine Arts, Engineering, Education, Food and Natural Resources, Nursing, Social and Behavioral Sciences, Public Health and Health Sciences, and Management. Our assessment focused on the following questions:

What went well?

- Reaching more students, connecting in surprising ways through technology, and seeing the students actively engaged in learning.

- Access to appropriate technology resources and ability to collaborate across units.

- Using technology to increase dynamic and cooperative teaching and learning.

- Increased productivity for both students and faculty.

What did not go well?

- Using/implementing technology makes incredible demands on faculty time.

- Logistics of accessing/using/moving equipment was daunting.

- Impersonal nature of technology (lack of face-to-face contact) and lack of student access to necessary resources (e.g., CD-ROM drives in public labs) inhibits the creation of excellent teaching and learning environments.

\section{What resources could you not find?}

- Almost all expressed frustration about access to resources.

- Support services were often inadequate even though they may have tried hard and meant well.

- Classroom space was inadequate to implement instructional technology.

- Lack of coordination and communication across campus about instructional technology. Who is doing what? 
- Lack of institutional support both in terms of incentives and rewards and in terms of physical resources.

What made it possible for you to start using instructional technology?

- When asked what allowed them to implement instructional technology, the most frequent response was "tenure." They felt that the effort required such a commitment of time and energy that it would never have been possible until they had that freedom.

- Others attributed their start to serendipitous early encounters with technology.

\section{What are the special pedagogical challenges?}

- Evaluation of instructional technology projects, especially distance education.

- Incredible time demands of creating and implementing instructional technology.

- Positive and negative impacts on students learning. Technology can create dynamic demonstrations and opportunities for a wider variety of learning styles, but it can also deprive students of personal contact and support. How does one balance the conflicting experiences?

What topics of instructional technology would you like to discuss with other faculty?

- Why are we trying to use technology? Is it worth it? What is the administration's real goal? How does it fit our mission?

- How do we find access to necessary resources? How are funds allocated?

- Does it really improve teaching?

- What is the new role of faculty when using instructional technology (sage on the stage vs. guide on the side)?

- How do we build communication/community on campus around technology?

(Butcher, 1997) 